\title{
Outcomes for core decompression with multiple drilling of the osteonecrosis of the femoral head in patients with solid organ transplantation
}

\author{
Solid organ transplantasyonu hastalarında femur başı osteonekrozunun çoklu drilleme \\ ile kor dekompresyon sonuçları
}

\author{
Bahtiyar Haberal, MD (D), Orcun Şahin, MD (D), Ekin Kaya Şimşek, MD (D), \\ Ateş Mahmuti, MD D, İsmail Cengiz Tuncay, MD $\mathbb{D}$ \\ Department of Orthopedics and Traumatology, Başkent University, Faculty of Medicine, Ankara, Turkey
}

\begin{abstract}
Objectives: This study aims to investigate the clinical and radiological outcomes of core decompression surgery performed with multiple drilling in solid organ transplantation patients with osteonecrosis of femoral head (ONFH) and evaluate the effectiveness of this procedure in regard to duration of corticosteroid use and stage of osteonecrosis.
\end{abstract}

Patients and methods: A total of 22 solid organ transplantation (kidney, liver or heart) patients (14 males, 8 females; mean age 43.3 years; range, 23 to 67 years) who were scheduled to undergo core decompression surgery with multiple drilling for ONFH were evaluated. Patients' Harris hip scores (HHSs) and radiographic data including Association Research Circulation Osseous (ARCO) staging and Kerboul grading were retrospectively reviewed at pre- and postoperative controls.

Results: Patients were followed-up for mean 34.3 months (range, 12 to 76 months). Two patients $(9.09 \%)$ were performed total hip arthroplasty. These two patients' Kerboul grade was 3. There was no statistically significant relationship between preoperation and postoperative final control in terms of ARCO staging. There was no statistically significant difference between pre- and postoperative HHSs.

Conclusion: Although multiple drilling is a safe and minimally invasive surgery, its effect is limited, particularly in solid organ transplantation patients with ONFH due to long-term corticosteroid use. Therefore, solid organ transplantation patients should be closely monitored in terms of ONFH development.

Keywords: Avascular necrosis; multiple drilling; outcome; transplantation.

\section{ÖZ}

Amaç: Bu çalışmada femur başı osteonekrozu (FBO) olan solid organ transplantasyonu hastalarında çoklu drilleme ile yapılan kor dekompresyon cerrahisinin klinik ve radyolojik sonuçları araştırıld $_{1}$ ve bu işlemin kortikosteroid kullanım süresi ve osteonekroz evresi açısından etkililiği değerlendirildi.

Hastalar ve yöntemler: Femur başı osteonekrozu için çoklu drilleme ile kor dekompresyon cerrahisi planlanan toplam 22 solid organ transplantasyonu (kalp, karaciğer veya böbrek) hastası (14 erkek, 8 kadın; ort. yaş 43.3 yıl; dağılım, 23-67 yıl) değerlendirildi. Hastaların Harris kalça skorları (HKS'leri) ve Kemik Dolaşımını Araştırma Birliği (ARCO) evrelemesi ve Kerboul evrelemesi dahil radyolojik verileri ameliyat öncesi ve sonrası kontrollerde retrospektif olarak incelendi.

Bulgular: Hastalar ortalama 34.3 ay (dağılım, 12-76 ay) takip edildi. İki hastaya (\%9.09) total kalça artroplastisi uygulandı. Bu iki hastada Kerboul evresi 3 idi. ARCO evrelemesi açısından ameliyat öncesinde ve sonrasındaki son kontrol arasında istatistiksel olarak anlamlı ilişki yoktu. Ameliyat öncesi ve sonrası HKS'leri arasında istatistiksel olarak anlamlı farklılık yoktu.

Sonuç: Çoklu drilleme güvenli ve minimal invaziv bir cerrahi olsa da özellikle uzun süreli kortikosteroid kullanımı nedeniyle FBO'su olan solid organ transplantasyonu hastalarında etkisi sinırlıdır. Bu nedenle, solid organ transplantasyonu hastaları FBO gelişimi açısından yakından takip edilmelidir.

Anahtar sözcïkler: Avasküler nekroz; çoklu drilleme; sonuç; transplantasyon. 
Osteonecrosis of the femoral head (ONFH) is a progressive and devastating disease of the hip joint that may lead to complete deterioration which results in walking disability, contractures and pain. ${ }^{[1]}$ Although several hypotheses have been proposed in the literature, the exact pathogenic mechanisms of ONFH and a gold-standard treatment methodology have not been described yet. Hence, it is one of the most controversial problems of orthopedic surgery that causes severe burden for medical professionals.

Postoperative immunosuppressive regimens including corticosteroids after solid organ transplantation have been commonly accepted as a major risk factor for ONFH. Therefore, solid organ transplantation patients are considered to be at potential risk for ONFH with a reported prevalence of as high as $20 \% .^{[2-5]}$ Although numerous reports describe corticosteroids as a major risk factor, there is still controversy on the role of predisposing factors and the total corticosteroid dose administered in the development of ONFH.

The treatment for ONFH remains controversial in the literature including different conservative methodologies and surgical procedures. Surgical interventions include core decompression with multiple drilling, vascularized or non-vascularized bone-grafting, muscle pedicle grafting, rotational osteotomy, and total hip arthroplasty (THA) ${ }^{[6]}$ Core decompression surgery with multiple drilling is a simple and cost-effective procedure for the treatment of particularly early-stage ONFH that can be safely performed percutaneously, under image intensifier guidance. Although there have been several reports in the literature about the outcomes of multiple drilling, the results are not comparable because of the heterogeneous study populations, different outcome measures and follow-up periods. For this reason, studies with homogenous study populations with one single etiological factor for ONFH and with long follow-up periods are needed in order to understand the real efficacy of multiple drilling surgery.

Hence, in this study, we aimed to investigate the clinical and radiological outcomes of core decompression surgery performed with multiple drilling in solid organ transplantation patients with ONFH and evaluate the effectiveness of this procedure in regard to duration of corticosteroid use and stage of osteonecrosis.

\section{PATIENTS AND METHODS}

A total of 28 patients with solid organ transplantation (kidney, liver or heart), who were scheduled to undergo core decompression surgery with multiple drilling for ONFH at Medicine Faculty of Başkent University between April 2009 and November 2016 were included in this retrospective study. Two patients who had ONFH due to multiple etiologic factors, three patients who were lost to follow-up, and one patient who had rejection were excluded. Thus, 22 patients (14 males, 8 females; mean age 43.3 years; range, 23 to 67 years) were included in the final analysis. The study protocol approval is not applicable because of the retrospective design. A written informed consent was obtained from each patient. The study was conducted in accordance with the principles of the Declaration of Helsinki.

Diagnosis of ONFH was confirmed with magnetic resonance imaging (MRI) for all patients based on bandlike abnormal signals, and/or band-like hypointense zones on $\mathrm{T}_{1}$-weighted images. ${ }^{[7]}$ The main indication for surgical decompression of ONFH with multiple drilling was difficulty in walking and/or pain which did not respond to any conservative treatment. To prevent any rejection of solid organ transplantation, long-term corticosteroid use for the purpose of immunosuppression was the main etiological factor of ONFH for all patients. Patients who had ONFH due to multiple factors or one single factor other than corticosteroid use, patients with less than one year of follow-up, or those who had any rejection of the transplantation or any previous hip surgery were excluded.

Core decompression surgeries were performed by multiple drilling technique previously described in the literature by Kim et al. ${ }^{[8]}$ All were performed with patients under general anesthesia and in the supine position by two surgeons experienced in hip surgery. A 2 to $3 \mathrm{~cm}$ straight lateral incision was made from the tip of the greater trochanter distally. A $2.5 \mathrm{~mm}$ Kirschner pin was inserted minimum four times toward the anterolateral and superolateral necrotic zones of the femoral head until it was $0.5 \mathrm{~cm}$ beneath the subchondral bone, as observed with $\mathrm{C}$-arm radiography. Gentle passive mobilization of the hip and knee began at seventh postoperative day, while active mobilization was initiated at four weeks postoperatively. The femoral head was protected from weight-bearing for three months with patients using a wheelchair or two crutches; gradual weightbearing with the use of crutches was allowed after three months.

Patients' data including demographics (age, gender, follow-up period, time of transplantation and duration of corticosteroid use) were retrospectively reviewed by one investigator, using computerized patient database and medical records. 
Clinical follow-up was carried out for every three and six months during the first and second year, respectively; and annually, thereafter. Harris hip scores (HHSs) were identified before the surgery and at final follow-up. ${ }^{[9]}$ All HHSs were determined by an investigator blinded to the clinical outcomes. Excellent, good, fair and poor results were defined as HHS over 90, 80-89, 70-79 and below 70, respectively. A clinical failure was defined as a HHS below 80 or if the patients needed further surgical procedure such as THA or osteotomy for any reason.

Early and late complications including prolonged drainage, infection, pathologic fracture, progressive pain and walking disability leading to THA or any mortality were recorded accordingly from the medical charts for each patient.

Patients' radiographic data were reviewed using the Picture Archiving and Communication System (InterPACS Dicom Viewer v3.0.1, Toronto, ON, Canada) of the hospital network. Anteroposterior and frog lateral radiographs were taken before the surgery and at each clinical follow-up. All radiographs were graded according to the system of the Association Research Circulation Osseous (ARCO).${ }^{[10]}$ A radiographic failure was defined as the onset or the progression of collapse or progressive osteoarthritis according to follow-up radiographs.

The extent of osteonecrosis was estimated by a modification of the combined necrotic angle method of Kerboul et al. ${ }^{[1]}$ The necrotic angle was measured on coronal and sagittal MRI scans instead of anteroposterior and lateral radiographs. The midcoronal (A) and midsagittal sections (B), which show the largest diameter of the femoral head, were used for the measurements (Figure 1). The sum of the two angles $(\mathrm{A}+\mathrm{B})$ was then calculated as the "combined necrotic angle". On the basis of the magnitude of the combined necrotic angle, hips were classified into four categories: grade $1\left(<200^{\circ}\right)$, grade $2\left(200^{\circ}\right.$ to $\left.249^{\circ}\right)$, grade $3\left(250^{\circ}\right.$ to $\left.299^{\circ}\right)$ and grade $4\left(\geq 300^{\circ}\right)$.

\section{Statistical analysis}

Statistical analyses were performed using the Statistical Package for the Social Sciences version 11.0 software (SPSS Inc., Chicago, IL, USA). Comparison between the pre- and postoperative HHSs and ARCO grades were performed using a paired sample t-test. The results were expressed as number of observations (n) with mean values and ranges. Significance level was set at a $p$ value $<0.05$.

\section{RESULTS}

The mean follow-up period for the study group was 34.3 months (range, 12 to 76 months). There were seven patients $(31.8 \%)$ with bilateral ONFH. There were 14 kidney, six liver and two heart transplantation patients. The mean age of the patients when they had transplantation surgery was 35.68 years (range, 19 to 64 years). The only predisposing factor for ONFH was prednisolone use (Deltacortril, Pfizer, New York, USA) for all patients. The mean duration and dosage of corticosteroid use was 21.5 months (range, 12 to 63 months) and $7.4 \mathrm{mg}$ (range, 5 to $20 \mathrm{mg}$ ), respectively. There were only two patients with over five years of follow-up in the final control who had ceased corticosteroid use after transplantation.
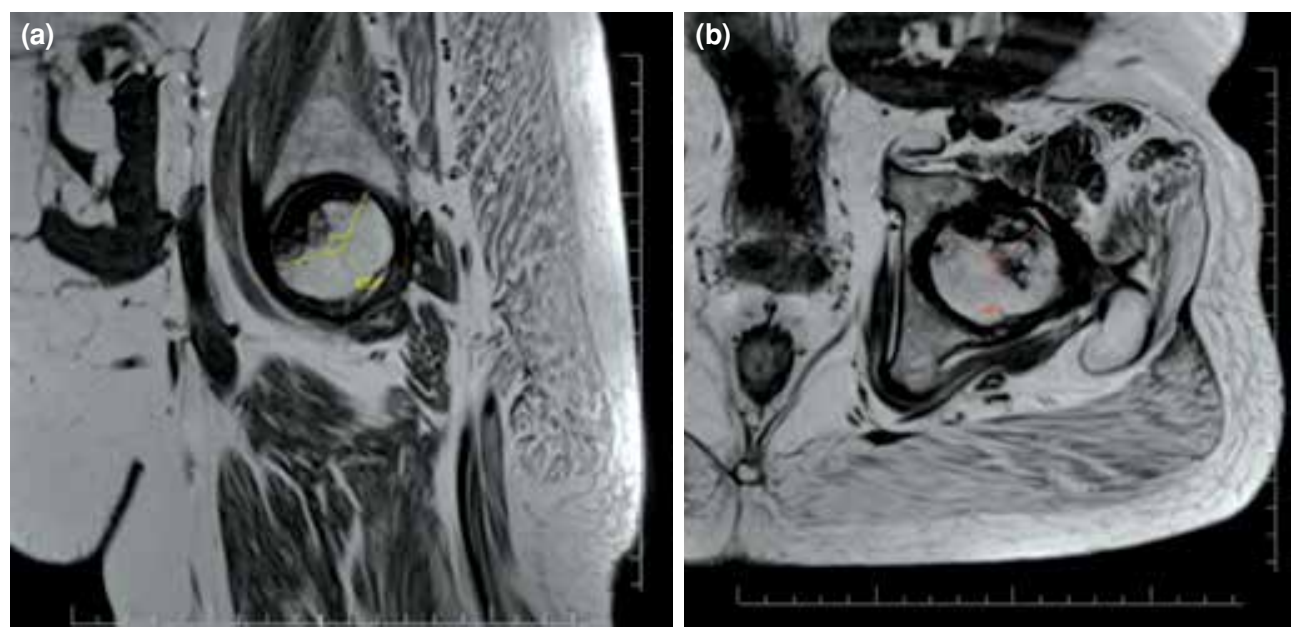

Figure 1. Calculation of combined necrotic angle from magnetic resonance imaging scans with modified Kerboul method. (a) Angle of necrotic area in midcoronal image. (b) Angle of necrotic area in midsagittal image. Combined necrotic angle: $A+B$. 

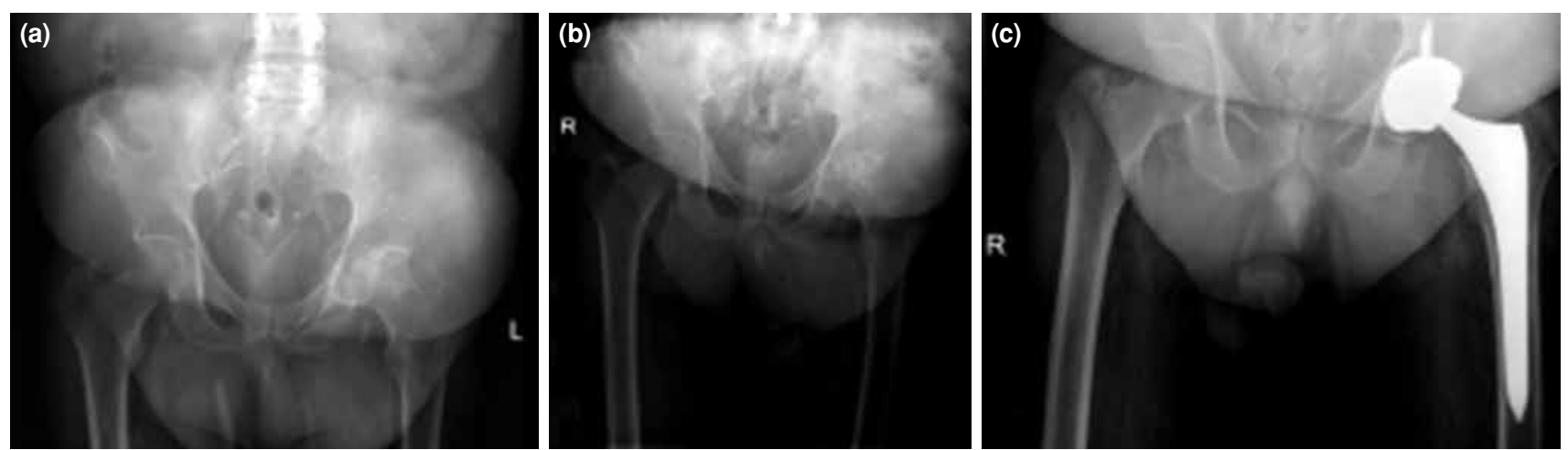

Figure 2. Radiographic images of a 44-year-old male patient with renal transplantation. (a) Preoperative, (c) after core decompression, (c) after total hip replacement.

There were no early complications for the study group. Two patients $(2 / 22,9.09 \%)$ (one heart and one kidney transplantation) who had severe progressive osteonecrosis leading to coxarthrosis were treated with total hip replacement surgery (Figure 2).

The pre- and postoperative mean HHSs in regard to ARCO staging and clinical results were summarized in Table I as either excellent, good, fair or poor with radiographic failure rates. There was no statistically significant difference between pre- and postoperative HHSs $(p=0.692)$. There were eight grade 1 hips, 15 grade 2 hips, and seven grade 3 hips, while there was no grade 4 hip according to the modified Kerboul grading system. All patients who underwent THA surgeries (2/30 hips, one hip with ARCO stage 3C and one hip with ARCO stage 4) had Kerboul grade $3(2 / 7,28,5 \%)$ osteonecrosis of the femoral head. The statistical comparison results of ARCO staging revealed no statistically significant difference between pre- and postoperative radiographic stages $(p=0.437)$.

\section{DISCUSSION}

Osteonecrosis of femoral head is one of the most important orthopedic problems that need meticulous treatment strategies. If left unattended, it has the potential to progress into severe coxarthrosis that leads to THA, which increases medical costs devastatingly. For this reason, in the current study, the clinical and radiographic outcomes of core decompression of ONFH with multiple drilling in solid organ transplantation patients were analyzed for a minimum of one-year follow-up. To our knowledge, this is one of the first studies in the literature that specifically evaluates multiple drilling in patients with solid organ transplantation.

TABLE I

Kerboul grades and Association Research Circulation Osseous stages of study groups with clinical outcomes according to Harris hip scores

\begin{tabular}{|c|c|c|c|c|c|c|c|c|}
\hline \multirow[b]{2}{*}{$\begin{array}{l}\text { Kerboul } \\
\text { Grade }\end{array}$} & \multirow[b]{2}{*}{ Stage (ARCO) } & \multicolumn{2}{|c|}{ Harris hip scores* } & \multicolumn{4}{|c|}{ Clinical results } & \multirow[b]{2}{*}{ THR $(n=2)$} \\
\hline & & Preoperation & Follow-up & Excellent & Good & Fair & Poor & \\
\hline $1(n=8)$ & $1(n=4)$ & $68.3 \pm 4.0$ & $72.5 \pm 4.4$ & + & & & & \\
\hline $2(n=15)$ & $2 A(n=3)$ & $59.7 \pm 2.5$ & $64.3 \pm 4.9$ & & + & & & \\
\hline $3(n=7)$ & $2 B(n=2)$ & $56 \pm 8.5$ & $53 \pm 2.8$ & & + & & & \\
\hline \multirow[t]{5}{*}{$4(n=0)$} & $2 C(n=5)$ & $62.8 \pm 6.7$ & $63.8 \pm 6.1$ & & + & & & \\
\hline & $3 A(n=3)$ & $59.3 \pm 12.7$ & $68.7 \pm 17.0$ & & + & & & \\
\hline & $3 B(n=1)$ & $52 \pm 7.3$ & $57 \pm 10.4$ & & + & & & \\
\hline & $3 C(n=10)$ & $56 \pm 11.0$ & $61.4 \pm 9.2$ & & + & & & 1 \\
\hline & $4(n=2)$ & $54 \pm 19.8$ & $62 \pm 17.0$ & & + & & & 1 \\
\hline Total & 30 & & & & & & & \\
\hline
\end{tabular}

\footnotetext{
* Statistical comparison results were mentioned in text; ARCO: Association Research Circulation Osseous; THR: Total hip replacement.
} 
Although there have been various risk factors identified in the literature for ONFH, the exact etiology still remains a matter of discussion. Corticosteroid use was accepted as a major predisposing factor for the development of ONFH for a very long-time. Nevertheless, the literature contains scarce and inconclusive data about the dosage and duration of these drugs, particularly after solid organ transplantation. A study by Colwell et al. ${ }^{[12]}$ stated that high doses ( $>30 \mathrm{mg} /$ day) and longer duration of corticosteroid treatment were the most important predictors for the development of ONFH. Another study by Lausten et al. ${ }^{[13]}$ detected an 11.2\% incidence of ONFH among 750 patients with renal-transplantations with a cumulative dose of $12.5 \mathrm{~g} /$ day after one year of transplantation surgery. Other studies in the literature also support these findings with up to $20 \%$ incidence of ONFH with a minimum cumulative dose of $2.5 \mathrm{~g} /$ day for at least three months. ${ }^{[7,13,14]}$ Nevertheless, some studies stated the opposite. In a prospective study by LopezBen et al., ${ }^{[15]} 48$ patients with renal transplantation were followed-up radiographically for six months to determine if there was any ONFH. At final control, only two patients $(4 \%)$ of ONFH were detected. In conclusion, the authors stated that a lower incidence of ONFH was detected in renal transplantation patients free from the cumulative dose of corticosteroid use. In general, discussion is ongoing about corticosteroid use and the cumulative dose that lead to ONFH. Our study had comparable results with the literature. The mean corticosteroid dose in our study was $7.5 \mathrm{mg} /$ day. So, we believe that even low-doses of corticosteroid have the potential to develop ONFH in solid organ transplantation patients.

In the last decade, steroid-sparing regimens gained popularity for solid organ transplantation patients to prevent steroid-induced ONFH. Although some studies favored the use of these regimens to decrease the incidence of $\mathrm{ONFH}_{,}{ }^{[16,17]}$ some studies did not support them. ${ }^{[18]}$ Although the literature contains inconclusive data, in our institution, solid organ transplantation patients were recently administered these steroid-sparing regimens to prevent any ONFH. Therefore, we believe that any chance of decreasing the incidence of ONFH is worth a try, no matter its cost-effectiveness.

Treatment strategies for ONFH are also an issue of discussion in the literature. Core decompression is one of the most commonly applied surgical procedures, which enables reducing the pressure in the femoral head to achieve normal blood flow of the femoral head. In the last decade, core decompression with multiple drilling has started to gain popularity compared with the standard core decompression technique. Kim et al. ${ }^{[8]}$ described this technique with multiple small drillings with a $3 \mathrm{~mm}$ Steinman pin to perform core decompression, which theoretically reduced proximal femur weakening compared to the standard technique. Thus, this approach is believed to be a simple procedure that can be safely performed percutaneously, under image intensifier guidance and with minimal risk of subtrochanteric fracture. For this reason, in our institution, multiple drilling is the first choice of surgical treatment particularly in patients with early stage of ONFH. Nevertheless, we believe that the success of the treatment is largely dependent on the causes and the stage of the lesion. ${ }^{[1]}$

In the literature, the effectiveness of multiple drilling in patients with ONFH is confusing with non-comparable outcome measures. Although various studies had favorable outcomes with good to excellent HHSs and better radiographic stages, some studies clearly stated that multiple drilling has no real positive effect particularly in patients with low preoperative HHS and advanced stage of osteonecrosis. In a study by Wang et al., ${ }^{[19]} 45$ patients with stage 1-3A nontraumatic osteonecrosis had multiple drilling surgery. After a mean follow-up period of 27.6 months, the authors stated that multiple drilling may be the treatment of choice with better HHS particularly in early stages of osteonecrosis. In another study by Bozic et al., ${ }^{[20]}$ the effectiveness of multiple drilling was analyzed in patients with ONFH. The authors stated that although the surgery had limited effect for advanced-stage osteonecrosis, multiple drilling has to be the first-line treatment option for early stages with high HHSs. In our study, we had comparable results with the literature. Accordingly, all patients who underwent THA surgeries had high Kerboul osteonecrosis grades (all grade 3 ). We had no patients who underwent THA with Kerboul grades of 1 or 2 . Consequently, we believe that the osteonecrotic lesion size of the femoral head may be a good predictor for the poor follow-up outcomes leading to THA. Contrary to the studies that suggest multiple drilling, we believe that it has limited effect with no significant difference between pre- and postoperative HHSs particularly for high grade ONFH.

Our study has some limitations. First is the study's retrospective design. Prospective studies with larger study populations should be performed for more precise outcomes. Secondly, we had no comparison group to achieve a statistical comparison between multiple drilling and other core decompression techniques. Thirdly, the number of patients was 
inadequate according to stages to establish a definitive conclusion. Finally, minimum one-year follow-up may not be sufficient to analyze the exact outcomes of multiple drilling. Therefore, further studies with longer follow-up periods are needed to detect the long-term outcomes of ONFH in solid organ transplantation patients.

In conclusion, although multiple drilling is a safe, minimally invasive, and easy-to-apply surgical procedure, its effectiveness is limited particularly in patients with solid organ transplantation who have ONFH due to long-term corticosteroid usage. After a minimum of one-year follow-up, the clinical HHSs and radiographic stages of ONFH did not improve significantly. Consequently, solid organ transplantation patients should be closely monitored to prevent any ONFH.

\section{Acknowledgments}

The authors thank Dr. Pınar Ülgen, MD, for her assistance in data collection.

\section{Declaration of conflicting interests}

The authors declared no conflicts of interest with respect to the authorship and/or publication of this article.

\section{Funding}

The authors received no financial support for the research and/or authorship of this article.

\section{REFERENCES}

1. Karakaplan M, Gülabi D, Topgül H, Elmalı N. Does plateletrich plasma have a favorable effect in the early stages of steroid-associated femoral head osteonecrosis in a rabbit model? Eklem Hastalik Cerrahisi 2017;28:107-13.

2. Lieberman JR, Scaduto AA, Wellmeyer E. Symptomatic osteonecrosis of thehip after orthotopic liver transplantation. J Arthroplasty 2000;15:767-71.

3. Porayko MK, Wiesner RH, Hay JE, Krom RA, Dickson ER, Beaver $\mathrm{S}$, et al. Bone disease in liver transplant recipients: incidence, timing, and risk factors. Transplant Proc 1991;23:1462-5.

4. Papagelopoulos PJ, Hay JE, Galanis EC, Morrey BF. Total joint arthroplasty in orthotopic liver transplant recipients. J Arthroplasty 1996;11:889-92.

5. Horiuchi H, Hashikura Y, Hisa K, Saito N, Ikegami T, Nakazawa $Y$, et al. Osteonecrosis of the femoral head in Japanese adults after liver transplantation: a preliminary report. J Orthop Sci 2004;9:119-21.

6. Hong YC, Zhong HM, Lin T, Shi JB. Comparison of core decompression and conservative treatment for avascular necrosis of femoral head at early stage: a meta-analysis. Int J Clin Exp Med 2015;8:5207-16.

7. Fink B, Degenhardt S, Paselk C, Schneider T, Mödder U, Rüther W. Early detection of avascular necrosis of the femoral head following renal transplantation. Arch Orthop Trauma Surg 1997;116:151-6.

8. Kim SY, Kim DH, Park IH, Park BC, Kim PT, Ihn JC. Multiple drilling compared with core decompression for the treatment of osteonecrosis of the femoral head. Orthopaedic Proceedings 2004;86-B (Supp II):149.

9. Harris WH. Traumatic arthritis of the hip after dislocation and acetabular fractures: treatment by mold arthroplasty. An end-result study using a new method of result evaluation. J Bone Joint Surg [Am] 1969;51:737-55.

10. Sugano N, Atsumi T, Ohzono K, Kubo T, Hotokebuchi T, Takaoka K. The 2001 revised criteria for diagnosis, classification, and staging of idiopathic osteonecrosis of the femoral head. J Orthop Sci 2002;7:601-5.

11. Kerboul M, Thomine J, Postel M, Merle d'Aubigné R. The conservative surgical treatment of idiopathic aseptic necrosis of the femoral head. J Bone Joint Surg [Br] 1974;56:291-6.

12. Colwell CW Jr, Robinson CA, Stevenson DD, Vint VC, Morris BA. Osteonecrosis of the femoral head in patients with inflammatory arthritis or asthma receiving corticosteroid therapy. Orthopedics 1996;19:941-6.

13. Lausten GS, Jensen JS, Olgaard K. Necrosis of the femoral head after renal transplantation. Acta Orthop Scand 1988;59:650-4.

14. Kubo T, Yamazoe S, Sugano N, Fujioka M, Naruse S, Yoshimura $\mathrm{N}$, et al. Initial MRI findings of non-traumatic osteonecrosis of the femoral head in renal allograft recipients. Magn Reson Imaging 1997;15:1017-23.

15. Lopez-Ben R, Mikuls TR, Moore DS, Julian BA, Bernreuter WK, Elkins M, et al. Incidence of hip osteonecrosis among renal transplantation recipients: a prospective study. Clin Radiol 2004;59:431-8.

16. Schrem H, Barg-Hock H, Strassburg CP, Schwarz A, Klempnauer J. Aftercare for patients with transplanted organs. Dtsch Arztebl Int 2009;106:148-56.

17. Matas AJ, Kandaswamy R, Gillingham KJ, McHugh L, Ibrahim H, Kasiske B, et al. Prednisone-free maintenance immunosuppression-a 5-year experience. Am J Transplant 2005;5:2473-8.

18. Refaie AF, Mahmoud KM, Ismail AM, Sheashaa HA, Kamal AI, Ghoneim MA. Alemtuzumab preconditioning allows steroid-calcineurin inhibitor-free regimen in live-donor kidney transplant. Exp Clin Transplant 2011;9:295-301.

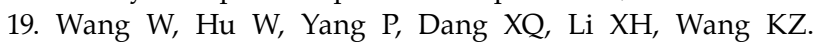
Patient-specific core decompression surgery for earlystage ischemic necrosis of the femoral head. PLoS One 2017;12:e0175366.

20. Bozic KJ, Zurakowski D, Thornhill TS. Survivorship analysis of hips treated with core decompression for nontraumatic osteonecrosis of the femoral head. J Bone Joint Surg [Am] 1999;81:200-9. 